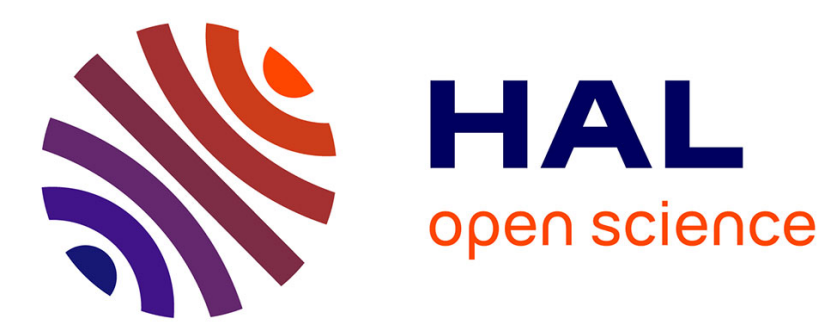

\title{
Refined sine theory including transverse normal stress in cylindrical bending.
}

P. Vidal, O. Polit

\section{To cite this version:}

P. Vidal, O. Polit. Refined sine theory including transverse normal stress in cylindrical bending.. Mechanics of Advanced Materials and Structures, 2013, 20 (6), pp.405-414. 10.1080/15376494.2011.627631 . hal-01366971

\section{HAL Id: hal-01366971 \\ https://hal.science/hal-01366971}

Submitted on 8 Jan 2018

HAL is a multi-disciplinary open access archive for the deposit and dissemination of scientific research documents, whether they are published or not. The documents may come from teaching and research institutions in France or abroad, or from public or private research centers.
L'archive ouverte pluridisciplinaire HAL, est destinée au dépôt et à la diffusion de documents scientifiques de niveau recherche, publiés ou non, émanant des établissements d'enseignement et de recherche français ou étrangers, des laboratoires publics ou privés. 


\title{
Refined Sine Theory Including Transverse Normal Stress in Cylindrical Bending
}

\author{
P. VIDAL and O. POLIT \\ LEME, Universite' Paris Ouest, Ville d'Avray, France
}

\begin{abstract}
Two new sine models including the transverse normal deformation are presented for the analysis of laminated plates with a cross-ply layout in cylindrical bending. A layer refinement for each component of the displacements is considered. The transverse shear strain is obtained by using a cosine function avoiding the use of shear correction factors. This kinematics accounts for the interlaminar continuity conditions on the interfaces between the layers for the transverse normal and shear stresses, and the boundary conditions on the upper and lower surfaces of the plate. Note that the number of unknowns is independent of the number of layers. The main topics are focused on the evaluation of the transverse normal and shear stresses by the constitutive relation. Mechanical and thermomechanical results within a closed-form solution technique are compared to elasticity reference solutions for thin and very thick plates.
\end{abstract}

Keywords: composite, refined sine model, transverse normal stress, Navier solution, thermomechanical analysis

\section{Introduction}

Composite and sandwich structures are widely used in industry due to their excellent mechanical properties, especially their high specific stiffness and strength. In this context, they can be subjected to severe mechanical and thermal conditions. For composite design, an accurate knowledge of displacements and stresses is required. Hence, it is important to take into account effects of the transverse shear deformation due to a low ratio of transverse shear modulus to axial modulus, or failure due to delamination. In fact, such effects can play an important role in the behavior of structures, and it is desirable to evaluate precisely their influence on local stress fields in each layer.

The aim of this article is to develop two models including the transverse normal deformation, so as to obtain accurate predictions for the behavior of laminated composite plates in cylindrical bending subjected to mechanical and thermal loading. This analysis is limited to the elasticity area in relation to small displacements. In this context, we put the emphasis on the need to take into account transverse normal effects, in particular for thermal conditions and for thick structures [1,2].

Several theories exist in the literature for composite and sandwich structures (beams and plates for the present scope). They have been extended to thermomechanical problems as well. The following classification is associated with the

Address correspondence to P. Vidal, LEME, Université Paris Ouest, 50 rue de Sèvres, Ville d'Avray 92410, France. E-mail: philippe.vidal@u-paris10.fr dependence on the number of degrees of freedom (DOFs) with respect to the number of layers:

- The Equivalent Single Layer approach (ESL): The number of unknowns is independent of the number of layers, but continuity of transverse shear and normal stresses is often violated at layer interfaces. We can distinguish classical laminate theory [3], first order shear deformation theory [4], composite laminates [5], and higher order theories [6-9]. In this family, some studies take into account transverse normal deformation ([10-16] with a higher order theory). In the framework of thermomechanical problems, different approaches have been developed: mixed [17] and displacement [18-21] formulations.

- The Layerwise approach (LW): The number of DOFs depends on the number of layers. This theory aims at overcoming the ESL shortcoming of allowing discontinuity of out-of-plane stresses on the interface layers. This approach was introduced in [22, 23]. For recent contributions, see [24-26].

Again, some models taking into account the transverse normal stress and strain have been developed: $[2,27]$ within a displacement based approach and $[16,28]$ within a mixed formulation. For thermomechanical analysis, readers can refer to [21] (for the displacement approach) and [29, 30] (for the mixed one).

In this framework, refined models have been developed in order to improve the accuracy of ESL models while avoiding the computational burden of the LW approach. Based on physical considerations and after some algebraic transformations, the number of unknowns becomes independent of 
the number of layers. Whitney [31] has extended the work of Ambartsumyan [32] for symmetric laminated composites with arbitrary orientation and a quadratic variation of the transverse stresses in each layer. A family of models, called zigzag models, was first employed in [33], then in [34-36]. More recently, it was modified and improved in [29, 37-41] with different-order kinematics assumptions, taking into account transverse normal strain.

Another way to improve the accuracy of results consists in a post-processing method (see [42-44]). It is based on the equilibrium equations and can be carried out in the framework of an ESL approach. The continuity of the transverse shear stresses is satisfied.

The literature just cited deals with only some aspects of the broad research activity about models for layered structures. An extensive assessment of different approaches has been made in [45-49]. About the particular point of the evaluation of transverse normal stresses, see [50,51].

In this work, two new models for laminated plate in cylindrical bending analysis are built, in order to have a low cost tool, that is efficient and simple to use. Our approach is associated with the ESL theory. The models are based on a refined shear deformation theory [52] avoiding the use of shear correction factors for laminates. They are based on the sine model [53]. The important new feature is the capability of the model to include the transverse normal deformation and stress. So, the transverse displacement is written under an $\mathrm{m}^{\text {th }}$-order expansion with a layer refinement, which avoids the Poisson locking mechanism [54]. For the in-plane displacement, the double superposition hypothesis from [55] is used: three local functions are added to the sine model. Finally, this process yields to a number of generalized displacements which is independent of the number of layers. All interface and boundary conditions are exactly satisfied for displacements, transverse shear and normal stresses. Therefore, this approach takes into account physical meaning.

This article is organized as follows. First, the mechanical and thermomechanical formulations for the different models are described. The continuity conditions are detailed. Then, numerical tests are performed upon various laminated plates, and in particular for very thick plates. A parametric study is given to show the effects of different parameters such as the length-to-thickness ratio. The accuracy of computations is also evaluated by comparison with an exact $3 \mathrm{D}$ theory for laminates in bending $[18,56]$. We put the emphasis on the direct calculation of the transverse shear and normal stresses from the constitutive relations.

Finally, other numerical examples are presented to demonstrate the effectiveness of the proposed models in coupled analysis. Computations for very thick plates of laminated composites are compared to exact 2D elasticity solutions under thermomechanical loading.

\section{Resolution of the Thermomechanical Problem}

\subsection{The Governing Equations for Thermomechanics}

Let us consider a plate occupying the domain $\mathcal{B}=[0, L] \times$ $\left[-\frac{b}{2} \leq x_{2} \leq \frac{b}{2}\right] \times\left[-\frac{h}{2} \leq z \leq \frac{h}{2}\right]$ in a Cartesian coordinate

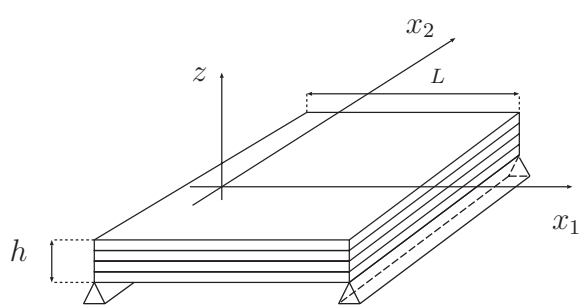

Fig. 1. The laminated plate and co-ordinate system.

$\left(x_{1}, x_{2}, z\right)$. The structure has a uniform thickness of height $h$. The plate is made of $N C$ layers of different linearly elastic materials. Each layer may be assumed to be orthotropic in the plate axes. The plane $\left(x_{1}, x_{2}\right)$ is the middle surface of the plate, and $z$ is the transverse axis, see Figure 1. This work is based upon a displacement approach for geometrically linear elastic plates.

\subsubsection{Constitutive Relation}

Each layer of the laminate is assumed to be orthotropic. Using matrix notation, the thermoelastic stress-strain law of the $k^{\text {th }}$ layer is given by

$$
\begin{aligned}
& {\left[\begin{array}{c}
\sigma_{11}^{(k)} \\
\sigma_{33}^{(k)} \\
\sigma_{13}^{(k)}
\end{array}\right]=} {\left[\begin{array}{ccc}
C_{11}^{(k)} & C_{13}^{(k)} & 0 \\
& C_{33}^{(k)} & 0 \\
s y m m & & C_{55}^{(k)}
\end{array}\right]\left[\begin{array}{c}
\varepsilon_{11}^{(k)}-\alpha_{11}^{(k)} \Delta T \\
\varepsilon_{33}^{(k)}-\alpha_{33}^{(k)} \Delta T \\
\varepsilon_{13}^{(k)}
\end{array}\right], } \\
& \text { i.e., }\left[\sigma^{(k)}\right]=\left[C^{(k)}\right]\left[\varepsilon^{(k)}\right],
\end{aligned}
$$

where $\Delta T$ is the temperature rise, $[\sigma]$ is the stress tensor, $[\varepsilon]$ is the strain tensor, the $C_{i j}$ are the $3 \mathrm{D}$ stiffness coefficients, and $\alpha_{i j}$ are the thermal expansion coefficients obtained after a transformation from the material axes to the Cartesian coordinate system.

\subsubsection{The Weak Form of the Boundary Value Problem}

Using the above matrix notation and for admissible virtual displacement $\vec{u}^{*} \in U^{*}$, the variational principle is defined by: find $\vec{u}$ in the space $U$ of admissible displacements such that

$$
\begin{aligned}
& -\int_{\mathcal{B}}\left[\varepsilon\left(\vec{u}^{*}\right)\right]^{T}[\sigma(\vec{u})] d \mathcal{B}+\int_{\mathcal{B}}\left[u^{*}\right]^{T}[f] d \mathcal{B}+\int_{\partial \mathcal{B}_{F}}\left[u^{*}\right]^{T}[F] d \partial \mathcal{B} \\
& =\int_{\mathcal{B}} \rho\left[u^{*}\right]^{T}[\ddot{u}] d \mathcal{B}, \quad \forall \vec{u}^{*} \in U^{*},
\end{aligned}
$$

where $[f]$ and $[F]$ are the prescribed body and surface forces applied on $\partial \mathcal{B}_{F} . \varepsilon\left(\vec{u}^{*}\right)$ is the virtual strain, and $\rho$ is the mass density.

\subsection{The Displacement Field for Laminated Plates in Cylindrical Bending}

Based on the sine function (see [57]), two models which take into account the transverse normal deformation are presented in this section. They are based on both various works on 
beams, plates and shells ([53, 57-60]), covering the refined theory, and the so-called 1,2-3 double-superposition theory developed in [55]. It also follows the local-global approach studied in [61, 62]. These refined models (see [63]) take into account the continuity conditions between layers of the laminate for both displacements and transverse shear stress, and the free conditions on the upper and lower surfaces owing to the Heaviside function. Here, the previous model [1] is improved by incoporating a refinement in the transverse displacement for each layer. It allows us to include the continuity of the transverse normal stress.

The kinematics of the two models is assumed to be of the following particular form, where the prime stands for the differentiation with respect to $x_{1}$ and $H$ is the Heaviside step function $(H(z)=1$ if $z \geq 0$ and $H(z)=0$ otherwise):

$$
\left\{\begin{aligned}
u_{1}\left(x_{1}, x_{2}, z\right)= & v_{0}\left(x_{1}\right)+z v_{1}\left(x_{1}\right)+f(z)\left(\omega_{2}\left(x_{1}\right)+w_{0}\left(x_{1}\right)^{\prime}\right) \\
& +g(z) v_{2}\left(x_{1}\right) \\
& +\sum_{k=1}^{N C}\left(\bar{u}_{l o c}^{(k)}\left(x_{1}, z\right)+\hat{u}_{l o c}^{(k)}\left(x_{1}, z\right)\right) \Delta H_{k} \\
u_{3}\left(x_{1}, x_{2}, z\right)= & \sum_{i=0}^{m} z^{i} w_{i}\left(x_{1}\right) \\
& +\sum_{k=1}^{N C}\left(g_{1}^{(k)}(z) w_{31}^{k}\left(x_{1}\right)+g_{2}^{(k)}(z) w_{32}^{k}\left(x_{1}\right)\right) \Delta H_{k},
\end{aligned}\right.
$$

where $\Delta H_{k}=\left(H\left(z-z_{k}\right)-H\left(z-z_{k+1}\right)\right)$ and $g(z)=z^{2}$.

In the classic approach, $w_{0}$ is the bending deflection following the $z$ direction, while $v_{0}$ is associated with the membrane displacement of a point of the middle surface, and $\omega_{2}$ is the shear bending rotation around the $x_{2}$ axis.

The local functions $\bar{u}_{l o c}^{(k)}$ and $\hat{u}_{l o c}^{(k)}$ are based on the first few Legendre polynomials such that

$$
\left\{\begin{array}{l}
\bar{u}_{l o c}^{(k)}\left(x_{1}, z\right)=\zeta_{k} u_{31}^{k}\left(x_{1}\right)+\left(-\frac{1}{2}+\frac{3 \zeta_{k}^{2}}{2}\right) u_{32}^{k}\left(x_{1}\right) \\
\hat{u}_{l o c}^{(k)}\left(x_{1}, z\right)=\left(-\frac{3 \zeta_{k}}{2}+\frac{5 \zeta_{k}^{3}}{2}\right) u_{33}^{k}\left(x_{1}\right) .
\end{array}\right.
$$

The local transverse functions are expressed as follows:

$$
\left\{\begin{array}{l}
g_{1}{ }_{w}^{(k)}(z)=\zeta_{k}^{m} \\
g_{2}{ }_{w}^{(k)}(z)=\zeta_{k}^{m+1}
\end{array}\right.
$$

where $m$ is the power associated to the transverse displacement in Eq. (3). The coordinate system is precised on Figure 2. A nondimensional transverse coordinate has been introduced by $\zeta_{k}=a_{k} z-b_{k}$, with $a_{k}=\frac{2}{z_{k+1}-z_{k}}, b_{k}=\frac{z_{k+1}+z_{k}}{z_{k+1}-z_{k}}$.

In the context of the sine model, we have $f(z)=\frac{h}{\pi} \sin \frac{\pi z}{h}$, and the derivative of this function will represent the transverse shear strain distribution due to bending. Hence, it is not necessary to introduce transverse shear correction factors.

At this stage, $5 \times N C+5+m$ generalized displacements are included in Eq. (3).

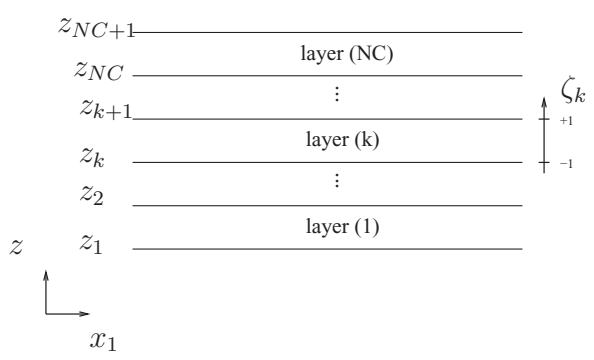

Fig. 2. Transverse coordinate of laminated beam.

\subsubsection{Stress and Displacement Continuity Conditions and Free Surface Conditions}

We next turn to the task of deriving relations between the kinematic unknowns from:

- lateral boundary conditions, and

- interlaminar continuity conditions for displacements, transverse shear and normal stresses.

For an interface layer $k \in\{2, \ldots, N C\}$, we have:

- Displacement continuity conditions as in [61]:

$$
\begin{gathered}
\bar{u}_{l o c}^{(k)}\left(x_{1}, z_{k}\right)=\bar{u}_{l o c}^{(k-1)}\left(x_{1}, z_{k}\right) k=2, \ldots, N C, \\
\hat{u}_{l o c}^{(k)}\left(x_{1}, z_{k}\right)=\hat{u}_{l o c}^{(k-1)}\left(x_{1}, z_{k}\right) \quad k=2, \ldots, N C .
\end{gathered}
$$

- Transverse displacement continuity conditions between two adjacent layers:

$$
u_{3}\left(x_{1}, x_{2}, z_{k}^{+}\right)=u_{3}\left(x_{1}, x_{2}, z_{k}^{-}\right) k=2, \ldots, N C .
$$

- Transverse shear stress continuity between two adjacent layers:

$$
\sigma_{13}^{(k)}\left(x_{1}, z_{k}^{+}\right)=\sigma_{13}^{(k-1)}\left(x_{1}, z_{k}^{-}\right) k=2, \ldots, N C .
$$

- Transverse normal stress continuity between two adjacent layers:

$$
\sigma_{33}^{(k)}\left(x_{1}, z_{k}^{+}\right)=\sigma_{33}^{(k-1)}\left(x_{1}, z_{k}^{-}\right) k=2, \ldots, N C .
$$

So, $5 \times(N C-1)$ conditions are imposed, which allow us to reduce the number of unknowns to $10+m$ generalized displacements.

Boundary conditions of the transverse shear and normal stresses on the upper and lower surfaces must also be verified. So, we have

$$
\begin{aligned}
& \sigma_{13}^{(1)}\left(x_{1}, z=-\frac{h}{2}\right)=0 \text { and } \sigma_{13}^{(N C)}\left(x_{1}, z=\frac{h}{2}\right)=0 \\
& \sigma_{33}^{(1)}\left(x_{1}, z=-\frac{h}{2}\right)=0 \text { and } \sigma_{33}^{(N C)}\left(x_{1}, z=\frac{h}{2}\right)=p_{u}\left(x_{1}\right)
\end{aligned}
$$


Furthermore, two models are distinguished by satisfying or not the following conditions on the derivative of the transverse normal stress on the upper and lower surfaces:

$$
\sigma_{33, z}^{(1)}\left(x_{1}, z=-\frac{h}{2}\right)=0 \text { and } \sigma_{33, z}^{(N C)}\left(x_{1}, z=\frac{h}{2}\right)=0
$$

These two models are denoted "SinRefs $33 \mathrm{c}-(\mathrm{m}+6) \mathrm{p}$ " and "SinRefs33c-ud- $(\mathrm{m}+4)$ p," respectively, relative to previous articles [1]. The novelty is about the introduction of $\sigma_{33}$ and the order of expansion of the transverse displacement. Furthermore, the difference between these two models consists in the additional constraint defined in Eq. (13). The SinRefs33c-ud$(\mathrm{m}+4) \mathrm{p}$ model satisfies this one. Finally, the number of generalized displacements is reduced to $m+6$ and $m+4$, which is independent of the number of layers.

\subsubsection{Relation between the Generalized Displacements}

As in [27], the terms related to the refinement layer in $u_{3}$ are neglected in the expression of $\varepsilon_{13}$ because they have no influence on the transverse shear strain. So, Eqs. (6), (7), (9), and (11) can be written under a $(3 * N C-1) \times(3 * N C-$ 1) linear system. The resolution of this system drives to the following relation between the generalized unknowns:

$$
\begin{array}{rl}
u_{3 i}^{k}\left(x_{1}\right)= & \beta_{i}^{k}\left(\omega_{2}\left(x_{1}\right)+w_{0}\left(x_{1}\right)^{\prime}\right) \\
& +\eta_{i}^{k}\left(v_{1}\left(x_{1}\right)+w_{0}\left(x_{1}\right)^{\prime}\right)+\delta_{i}^{k} u_{31}^{1}\left(x_{1}\right) \\
& +\mu_{i}^{k} v_{2}\left(x_{1}\right)+\sum_{j=1}^{m} \lambda_{i j}^{k} w_{j}\left(x_{1}\right)^{\prime}, \quad k=1, \ldots, N C, \\
i & i=1,2,3,
\end{array}
$$

with

$$
\delta_{1}^{1}=1, \beta_{1}^{1}=\eta_{1}^{1}=\lambda_{1 j}^{1}=\mu_{1}^{1}=0,
$$

where $\beta_{i}^{k}, \delta_{i}^{k}, \lambda_{i j}^{k}, \mu_{i}^{k}$, and $\eta_{i}^{k}(i=1,2,3)$ are the continuity coefficients. For more details about the determination of these coefficients, see [63].

Now, we must take into account the relations involving the transverse displacement and the transverse normal stress. Equations (8), (10), and (12) for the SinRefs33c-(m+6)p, and Eqs. (8), (10), (12), and (13) for the SinRefs33c-ud-(m+4)p can be written under a $(2 * N C) \times(2 * N C)$ and $(2 * N C+$ $2) \times(2 * N C+2)$ linear system respectively. It allows us to express $w_{3 \alpha}^{k}, \alpha=1,2, k=1, \ldots, N C$ with respect to the other generalized unknowns as

$$
\begin{aligned}
w_{3 \alpha}^{k}= & C_{v_{0}^{\prime}}^{\alpha(k)} v_{0}^{\prime}+C_{v_{1}^{\prime}}^{\alpha(k)} v_{1}^{\prime}+C_{v_{2}^{\prime}}^{\alpha(k)} v_{2}^{\prime}+C_{\omega_{2}^{\prime}}^{\alpha(k)} \omega_{2}^{\prime}+C_{u_{31}^{\prime}}^{\alpha(k)} u_{31}^{1}{ }^{\prime} \\
& +\sum_{j=1}^{m_{0}} C_{w_{j}}^{\alpha(k)} w_{j}+\sum_{j=0}^{m_{0}} C_{w_{j}^{\prime \prime}}^{\alpha(k)} w_{j}^{\prime \prime}+C_{p}^{\alpha(k)} p_{u}
\end{aligned}
$$

with $m_{0}=m$ (for SinRefs33c-(m+6)p), $m_{0}=m-2$ (for SinRefs33c-ud-(m+4)p).
For the SinRefs33c-ud- $(\mathrm{m}+4) \mathrm{p}$ model, we also have two other relations that are deduced from Eq. (13):

$$
\begin{aligned}
& \int w_{m-1}=C_{v_{0}^{\prime}}^{3(k)} v_{0}^{\prime}+C_{v_{1}^{\prime}}^{3(k)} v_{1}^{\prime}+C_{v_{2}^{\prime}}^{3{ }^{(k)}} v_{2}^{\prime}+C_{\omega_{2}^{\prime}}^{3{ }^{(k)}} \omega_{2}^{\prime}+C_{u_{31}^{\prime}}^{3{ }^{(k)}} u_{31}^{1^{\prime}} \\
& +\sum_{j=1}^{m-2} C_{w_{j}}^{3{ }^{(k)}} w_{j}+\sum_{j=0}^{m-2} C_{w_{j}^{\prime \prime}}^{3(k)} w_{j}^{\prime \prime}+C_{p}^{3(k)} p_{u} \\
& w_{m}=C_{v_{0}^{\prime}}^{4(k)} v_{0}^{\prime}+C_{v_{1}^{\prime}}^{4(k)} v_{1}^{\prime}+C_{v_{2}^{\prime}}^{4(k)} v_{2}^{\prime}+C_{\omega_{2}^{\prime}}^{4(k)} \omega_{2}^{\prime}+C_{u_{31}^{1}}^{4}{ }^{(k)} u_{31}^{1} \\
& +\sum_{j=1}^{m-2} C_{w_{j}}^{4}{ }^{(k)} w_{j}+\sum_{j=0}^{m-2} C_{w_{j}^{\prime \prime}}^{(k)} w_{j}^{\prime \prime}+C_{p}^{4^{(k)}} p_{u},
\end{aligned}
$$

where $C_{\times}^{j(k)}$ are the continuity coefficients associated to the transverse normal stress and the out of plane displacement. In Eqs. (15) and (16), the dependencies with respect to $x_{1}$ and $z$ are omitted.

Finally, the general expression of the displacements can be deduced for the two models under a unified formulation:

$$
\left\{\begin{aligned}
u_{1}\left(x_{1}, x_{2}, z\right)= & \mathcal{L}_{0}(z) v_{0}\left(x_{1}\right)+\mathcal{L}_{1}(z) v_{1}\left(x_{1}\right)+\mathcal{L}_{3}(z) \omega_{2}\left(x_{1}\right) \\
& +\mathcal{L}_{2}(z) v_{2}\left(x_{1}\right)+\mathcal{L}_{4}(z) u_{31}^{1}\left(x_{1}\right) \\
& +\sum_{j=0}^{m_{0}} \mathcal{L}_{5 j}(z) w_{j}\left(x_{1}\right)^{\prime} \\
u_{3}\left(x_{1}, x_{2}, z\right)= & \mathcal{G}_{0}(z) v_{0}\left(x_{1}\right)^{\prime}+\mathcal{G}_{1}(z) v_{1}\left(x_{1}\right)^{\prime}+\mathcal{G}_{3}(z) \omega_{2}\left(x_{1}\right)^{\prime} \\
& +\mathcal{G}_{2}(z) v_{2}\left(x_{1}\right)^{\prime}+\mathcal{G}_{4}(z) u_{31}^{1}\left(x_{1}\right)^{\prime} \\
& +\sum_{j=0}^{m_{0}}\left(\mathcal{G}_{5 j}(z) w_{j}\left(x_{1}\right)+\mathcal{G}_{6 j}(z) w_{j}\left(x_{1}\right)^{\prime \prime}\right) \\
& +\mathcal{G}_{7}(z) p_{u}\left(x_{1}\right)
\end{aligned}\right.
$$

The expressions of $\mathcal{L}_{\times}, \mathcal{G}_{\times}$are deduced from Eqs. (3), (14), (15), (16), and (17). Note that they are different for the two models.

\subsection{Closed-Form Solution}

A standard procedure is carried out to solve the problem. The thickness assumptions are introduced into the variational equation (Eq. (2)). Then, the variation with respect to the thickness coordinate is eliminated by integrating over each layer thickness. The strong form of the governing partial differential equations is obtained by integrating by parts the appropriate terms. Here, we will restrict the verification studies to problems for which a closed-form solution can be found. This means that the structural response can be explicitly written in a form which exactly satisfies all boundary conditions and the field equations. By restricting the problems to simplysupported plates consisting of an arbitrary number of orthotropic layers with a cross-ply lay-up, the general solution with a single term of the infinite series expansion is written in the form:

$$
\begin{aligned}
& \left\{v_{0}, v_{1}, v_{2}, \omega_{2}, u_{31}^{1}\right\}\left(x_{1}\right)=\left\{V_{0}, V_{1}, V_{2}, \Omega_{2}, U_{31}^{1}\right\} \cos \left(\frac{n \pi x_{1}}{L}\right), \\
& w_{i}\left(x_{1}\right)=W_{i} \sin \left(\frac{n \pi x_{1}}{L}\right), i=1, \ldots, m_{0},
\end{aligned}
$$

where $n$ is the number of half-waves in the $x_{1}$ direction. 
Table 1. $\bar{w}(L / 2,0), \bar{\sigma}_{11}(L / 2,-h / 2), \bar{\sigma}_{13 \max }$ for different values of $S-2$ layers $\left(0^{\circ} / 90^{\circ}\right)$

\begin{tabular}{|c|c|c|c|c|c|c|}
\hline S & & Exact & SinRefs $33 c-u d-9 p$ & Err & SinRefs $33 c-9 p$ & Err \\
\hline \multirow[t]{3}{*}{2} & $\bar{w}(L / 2,0)$ & 10.849 & 10.750 & $0.9 \%$ & 10.706 & $1.3 \%$ \\
\hline & $\left.\bar{\sigma}_{11}\right|_{-h / 2}$ & -8.805 & -8.798 & $0.08 \%$ & -9.932 & $12 \%$ \\
\hline & $\bar{\sigma}_{13 \max }$ & 1.164 & 1.210 & $3.9 \%$ & 1.251 & $7 \%$ \\
\hline \multirow[t]{3}{*}{4} & $\bar{w}(L / 2,0)$ & 4.695 & 4.685 & $0.2 \%$ & 4.683 & $0.2 \%$ \\
\hline & $\left.\bar{\sigma}_{11}\right|_{-h / 2}$ & -30.029 & -30.734 & $2.3 \%$ & -30.762 & $2.4 \%$ \\
\hline & $\bar{\sigma}_{13 \max }$ & 2.706 & 2.763 & $2.1 \%$ & 2.764 & $2.1 \%$ \\
\hline \multirow[t]{3}{*}{10} & $\bar{w}(L / 2,0)$ & 2.953 & 2.953 & $0.02 \%$ & 2.952 & $0.02 \%$ \\
\hline & $\left.\bar{\sigma}_{11}\right|_{-h / 2}$ & -176.528 & -177.041 & $0.3 \%$ & -177.047 & $0.3 \%$ \\
\hline & $\bar{\sigma}_{13 \max }$ & 7.266 & 7.383 & $1.6 \%$ & 7.384 & $1.6 \%$ \\
\hline
\end{tabular}

The external loading is assumed as $p_{u}\left(x_{1}\right)=p_{0} \sin \left(\frac{n \pi x_{1}}{L}\right)$.

Introducing the above functions into the $1 \mathrm{D}$ governing equation, the following system is obtained:

$$
[\mathbf{K}][\mathbf{q}]=[\mathbf{F}],
$$

with $[\mathbf{q}]^{T}=\left[\begin{array}{llllllll}V_{0} & V_{1} & V_{2} & \Omega_{2} & U_{31}^{1} & W_{0} & \cdots & W_{m_{0}}\end{array}\right]$. The calculation of $[\mathbf{K}]$ is given in the appendix.

\section{Numerical Results}

Several mechanical and thermomechanical tests for a large range of slenderness ratio are presented validating the present approach. Severe tests are considered with $\mathrm{S}=2$. They are compared with exact solutions [56]. We put the emphasis on the evaluation of the transverse normal and shear stresses calculated by the constitutive relation. Previous studies have already shown that is is necessary to take into account the transverse nomal stress for this type of cases $[1,2,39]$. In the following, only the SinRefs33c-9p and SinRefs33c-ud-9p models, which are the most relevant, are discussed. Note that the order of expansion of the SinRefs $33 c-u d-9 p$ model is greater than these of the SinRefs33c-9p model (see Eq. (15)), but the computational cost remains identical.

\subsection{Mechanical Analysis}

The tests are about simply supported symmetric and antisymmetric composite plates and is issued from [56]. It is detailed below:

Geometry: Composite cross-ply plates $\left(0^{\circ} / 90^{\circ}\right),\left(0^{\circ} / 90^{\circ} / 0^{\circ}\right)$, and $\left(0^{\circ} / 90^{\circ} / 0^{\circ} / 90^{\circ}\right)$; length to thickness ratio from $\mathrm{S}=2$ to $\mathrm{S}=10\left(S=\frac{L}{h}\right)$; All layers have the same thickness.

Boundary conditions: Simply supported plate in cylindrical bending subjected to sinusoidal load $p_{u}\left(x_{1}\right)=p_{0} \sin \frac{\pi x_{1}}{L}$.

\section{Material properties:}

$$
\begin{aligned}
& E_{L}=172.4 \mathrm{GPa}, E_{T}=6.895 \mathrm{GPa}, G_{L T}=3.448 \mathrm{GPa}, \\
& G_{T T}=1.379 \mathrm{GPa}, \nu_{L T}=v_{T T}=0.25,
\end{aligned}
$$

where $L$ refers to the fiber direction, $T$ refers to the transverse direction.

Results: The results $\left(\bar{w}, \bar{\sigma}_{11}, \bar{\sigma}_{13}\right)$ are made non-dimensional using:

$$
\begin{aligned}
\bar{w} & =\frac{100 E_{T} u_{3}(L / 2,0)}{S^{4} h p_{0}} \quad \bar{\sigma}_{11}=\frac{\sigma_{11}(L / 2, \pm h / 2)}{p_{0}} \\
\bar{\sigma}_{13} & =\frac{\left.\sigma_{13 \max }\right|_{x_{1}=0}}{p_{0}}
\end{aligned}
$$

The numerical results for deflection, in-plane normal stress

\begin{tabular}{|c|c|c|c|c|c|c|}
\hline $\mathrm{S}$ & & Exact & SinRefs $33 c-u d-9 p$ & Err & $\operatorname{SinRefs} 33 c-9 p$ & Err \\
\hline \multirow[t]{3}{*}{2} & $\bar{w}(L / 2,0)$ & 8.523 & 8.491 & $0.3 \%$ & 8.481 & $0.5 \%$ \\
\hline & $\left.\bar{\sigma}_{11}\right|_{-h / 2}$ & -6.878 & -6.753 & $1.8 \%$ & -6.775 & $1.5 \%$ \\
\hline & $\bar{\sigma}_{13}(0,0)$ & 0.534 & 0.532 & $0.3 \%$ & 0.531 & $0.5 \%$ \\
\hline \multirow[t]{3}{*}{4} & $\bar{w}(L / 2,0)$ & 2.887 & 2.886 & $0.03 \%$ & 2.887 & $0.02 \%$ \\
\hline & $\left.\bar{\sigma}_{11}\right|_{-h / 2}$ & -18.104 & -18.187 & $0.4 \%$ & -18.192 & $0.4 \%$ \\
\hline & $\bar{\sigma}_{13}(0,0)$ & 1.431 & 1.431 & $0.00 \%$ & 1.430 & $0.07 \%$ \\
\hline \multirow[t]{3}{*}{10} & $\bar{w}(L / 2,0)$ & 0.931 & 0.931 & $0.000 \%$ & 0.931 & $0.005 \%$ \\
\hline & $\left.\bar{\sigma}_{11}\right|_{-h / 2}$ & -73.630 & -73.675 & $0.06 \%$ & -73.674 & $0.06 \%$ \\
\hline & $\bar{\sigma}_{13}(0,0)$ & 4.238 & 4.239 & $0.01 \%$ & 4.238 & $0.01 \%$ \\
\hline
\end{tabular}
and transverse shear stress are given in Tables 1, 2, and 3 for the three cases. We observe that the two models perform quite well with respect to the exact solution even for the very

Table 2. $\bar{w}(L / 2,0), \bar{\sigma}_{11}(L / 2,-h / 2), \bar{\sigma}_{13}(0,0)$ for different values of $S-3$ layers $\left(0^{\circ} / 90^{\circ} / 0^{\circ}\right)$ 
Table 3. $\bar{w}(L / 2,0), \bar{\sigma}_{11}(L / 2,-h / 2), \bar{\sigma}_{13 \max }$ for different values of $\mathrm{S}-4$ layers $\left(0^{\circ} / 90^{\circ} / 0^{\circ} / 90^{\circ}\right)$

\begin{tabular}{|c|c|c|c|c|c|c|}
\hline $\mathrm{S}$ & & Exact & SinRefs $33 c-u d-9 p$ & Err & SinRefs $33 c-9 p$ & Err \\
\hline \multirow[t]{4}{*}{2} & $\bar{w}(L / 2,0)$ & 11.478 & 11.369 & $0.9 \%$ & 11.391 & $0.7 \%$ \\
\hline & $\left.\bar{\sigma}_{11}\right|_{-h / 2}$ & -9.053 & -9.701 & $7 \%$ & -9.714 & $7 \%$ \\
\hline & $\bar{\sigma}_{13 \max }$ & 1.061 & 1.063 & $0.1 \%$ & 1.064 & $0.2 \%$ \\
\hline & $\bar{w}(L / 2,0)$ & 4.180 & 4.174 & $0.1 \%$ & 4.176 & $0.1 \%$ \\
\hline \multirow[t]{3}{*}{4} & $\left.\bar{\sigma}_{11}\right|_{-h / 2}$ & -24.948 & -25.403 & $1.8 \%$ & -25.408 & $1.8 \%$ \\
\hline & $\bar{\sigma}_{13 \max }$ & 1.991 & 2.009 & $0.8 \%$ & 2.008 & $0.8 \%$ \\
\hline & $\bar{w}(L / 2,0)$ & 1.657 & 1.656 & $0.02 \%$ & 1.656 & $0.02 \%$ \\
\hline \multirow[t]{2}{*}{10} & $\left.\bar{\sigma}_{11}\right|_{-h / 2}$ & -116.554 & -116.815 & $0.2 \%$ & -116.816 & $0.2 \%$ \\
\hline & $\bar{\sigma}_{13 \max }$ & 5.528 & 5.606 & $1.4 \%$ & 5.606 & $1.4 \%$ \\
\hline
\end{tabular}

Table 4. $\bar{w}(L / 2,0), \bar{\sigma}_{11}(L / 2, h / 2), \bar{\sigma}_{13 \max }$ for $\mathrm{S}=2$ and $\mathrm{S}=4-2 / 3 / 4$ layers

\begin{tabular}{|c|c|c|c|c|c|c|c|}
\hline \multirow[b]{2}{*}{$\mathrm{NC}$} & & \multicolumn{3}{|c|}{$\mathrm{S}=2$} & \multicolumn{3}{|c|}{$S=4$} \\
\hline & & Exact & SinRefs33c-ud-9p(err) & SinRefs33c-9p (err) & Exact & SinRefs33c-ud-9p (err) & SinRefs33c-9p (err) \\
\hline \multirow[t]{3}{*}{2} & $\bar{w}$ & 34.455 & $33.069(4 \%)$ & $33.071(4 \%)$ & 42.888 & $42.786(0.2 \%)$ & $42.772(0.2 \%)$ \\
\hline & $\left.\bar{\sigma}_{11}\right|_{h / 2}$ & 399.697 & $397.449(0.5 \%)$ & $400.149(0.1 \%)$ & 638.753 & $637.888(0.1 \%)$ & $638.176(0.1 \%)$ \\
\hline & $\bar{\sigma}_{13 \max }$ & 164.987 & $156.244(5 \%)$ & $156.641(5 \%)$ & 136.699 & $137.827(0.8 \%)$ & $137.961(0.9 \%)$ \\
\hline \multirow[t]{3}{*}{3} & $\bar{w}$ & 25.980 & $26.361(1 \%)$ & $26.438(1.7 \%)$ & 3.615 & $3.628(0.3 \%)$ & $3.629(0.4 \%)$ \\
\hline & $\left.\bar{\sigma}_{11}\right|_{h / 2}$ & 746.486 & $833.935(11 \%)$ & $833.480(11 \%)$ & 281.110 & $286.647(2 \%)$ & $286.849(2 \%)$ \\
\hline & $\bar{\sigma}_{13 \max }$ & 50.961 & $50.881(0.1 \%)$ & $50.875(0.1 \%)$ & 21.417 & $21.427(0.04 \%)$ & $21.425(0.04 \%)$ \\
\hline \multirow[t]{3}{*}{4} & $\bar{w}$ & 20.065 & $19.640(2 \%)$ & $19.808(1 \%)$ & 20.278 & $20.266(0.06 \%)$ & $20.277(0.01 \%)$ \\
\hline & $\left.\bar{\sigma}_{11}\right|_{h / 2}$ & 639.828 & $633.698(0.9 \%)$ & $634.243(0.8 \%)$ & 898.504 & $898.305(0.02 \%)$ & $898.378(0.01 \%)$ \\
\hline & $\bar{\sigma}_{13 \max }$ & 208.733 & $188.006(9 \%)$ & $187.753(10 \%)$ & 134.451 & $135.054(0.4 \%)$ & $134.984(0.4 \%)$ \\
\hline
\end{tabular}
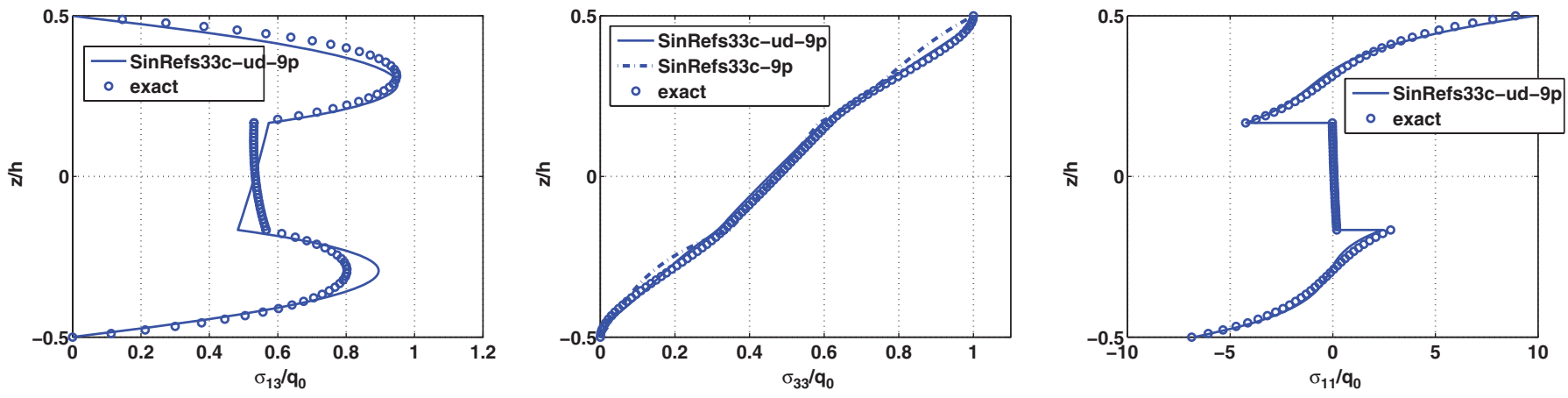

Fig. 3. Distribution of $\bar{\sigma}_{13}$ (left), $\bar{\sigma}_{33}$ (middle), and $\bar{\sigma}_{11}$ (right) along the thickness $-\mathrm{S}=2$ - three layers $\left(0^{\circ} / 90^{\circ} / 0^{\circ}\right)($ color figure available online).
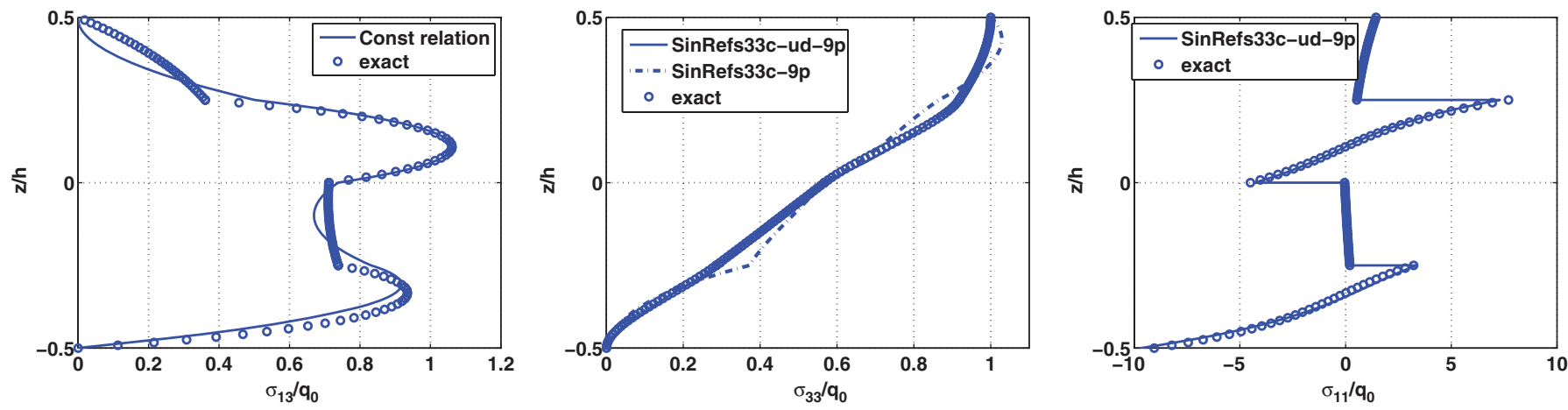

Fig. 4. Distribution of $\bar{\sigma}_{13}$ (left), $\bar{\sigma}_{33}$ (middle), and $\bar{\sigma}_{11}$ (right) along the thickness $-\mathrm{S}=2$-four layers $\left(0^{\circ} / 90^{\circ} / 0^{\circ} / 90^{\circ}\right)($ color figure available online). 

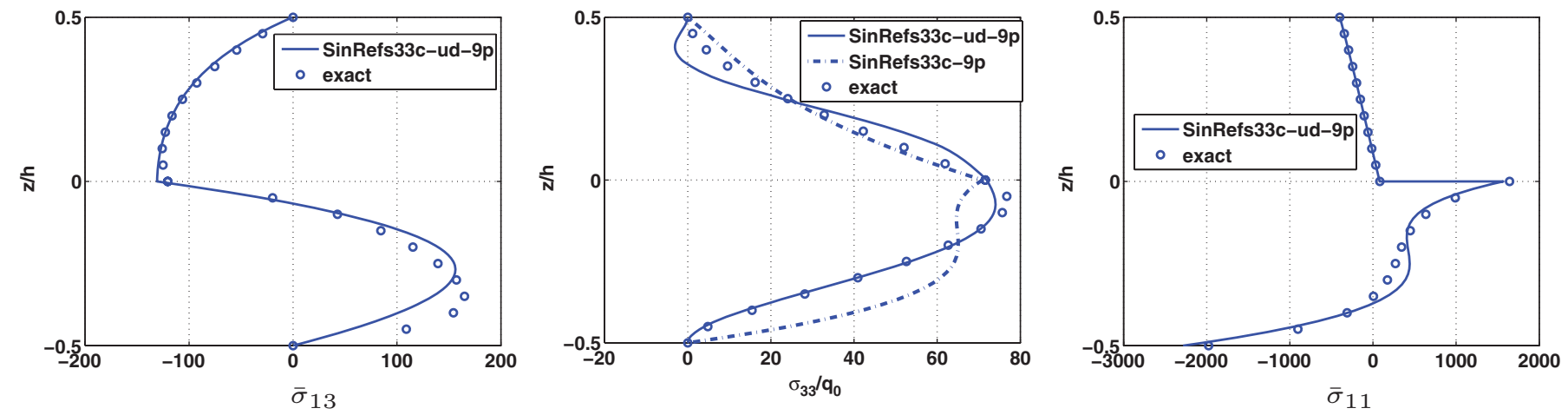

Fig. 5. Distribution of $\bar{\sigma}_{13}$ (left), $\bar{\sigma}_{33}$ (middle), and $\bar{\sigma}_{11}$ (right) along the thickness $-\mathrm{S}=2-$ two layers $\left(0^{\circ} / 90^{\circ}\right)-\operatorname{SinRefs} 33 \mathrm{c}-\mathrm{ud}-9 \mathrm{p}$ (color figure available online).

thick case. These models give similar results except for the two layer case where the SinRefs33c-ud-9p is better. For this one, the error on the maximal transverse shear stress is less than $3.9 \%$ regardless of the length to thickness ratio and the stacking sequence. Concerning the transverse displacement, the maximal error is $0.9 \%$.

The variation of the normalized in-plane, transverse shear and normal stresses through the thickness $(S=2)$ are presented in Figures 3 and 4 for further comparison. The variation of the transverse shear stress deduced from the constitutive relation yields satisfactory distributions even for the very thick plate, without computational cost at the post-processing level. The accuracy of the transverse normal stress is also very good for both symmetric and antisymmetric structures (all results are not presented here for brevity). The SinRefs33c-ud-9p model, where the slope at the upper and lower surface is imposed, improves the accuracy of this result (cf. Figures 3 and 4 [middle]). Note that the two models take into account the nonsymmetrical variation of the transverse shear and the in-plane stress through the thickness (symmetric stacking sequence). They have the capability to capture the out-of-plane stresses.

\subsection{Thermomechanical Analysis}

In this section, the accuracy of the present theory is assessed in thermomechanical analysis. The problem is the same as in the previous section. But, the plate is subjected to a temperature field as follows: $T\left(x_{1}, z\right)=T_{\max } \frac{2 z}{h} \sin \left(\frac{\pi x_{1}}{L}\right)$. The thermal expansion coefficients in the fiber and normal direction are such that $\frac{\alpha_{T}}{\alpha_{L}}=1125$.

As in [30], we define the dimensionless quantities:

$\bar{w}=\frac{h u_{3}(L / 2, z)}{\alpha_{L} T_{\max } L^{2}} \quad \bar{\sigma}_{11}=\frac{\sigma_{11}(L / 2, z)}{\alpha_{L} E_{T} T_{\max }} \quad \bar{\sigma}_{13}=\frac{\sigma_{13}(0, z)}{\alpha_{L} E_{T} T_{\max }}$

The reference results have been obtained from the thermomechanical solution given in [64].

Table 4 shows that the two models are very efficient and accurate, even for the very thick beam. For $S=4$, the percent error does not exceed $2 \%$ for all cases. In particular, the transverse shear stress is very well estimated. For the very thick case, the results remain satisfactory.

Figures 5, 6, and 7 give the distribution of the in-plane, transverse normal, and shear stresses for the two-layer and four-layer cases. Again, the SinRefs33c-ud-9p results are in very good agreement with the exact solution. Note that the transverse normal stress calculated from the constitutive relation with the two models is also well estimated even for the very thick case. In particular, the nonsymmetrical variation is taken into account, and the accuracy of the maximum value is good.
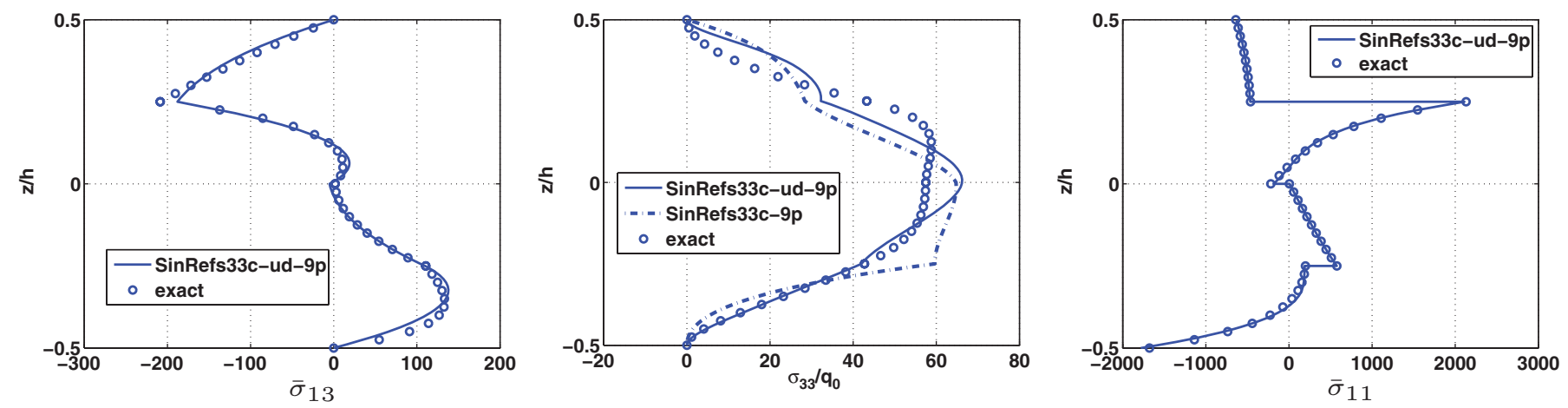

Fig. 6. Distribution of $\bar{\sigma}_{13}$ (left), $\bar{\sigma}_{33}$ (middle), and $\bar{\sigma}_{11}$ (right) along the thickness $-\mathrm{S}=2$-four layers $\left(0^{\circ} / 90^{\circ} / 0^{\circ} / 90^{\circ}\right)-$ SinRefs $33 \mathrm{c}-$ ud-9p (color figure available online). 

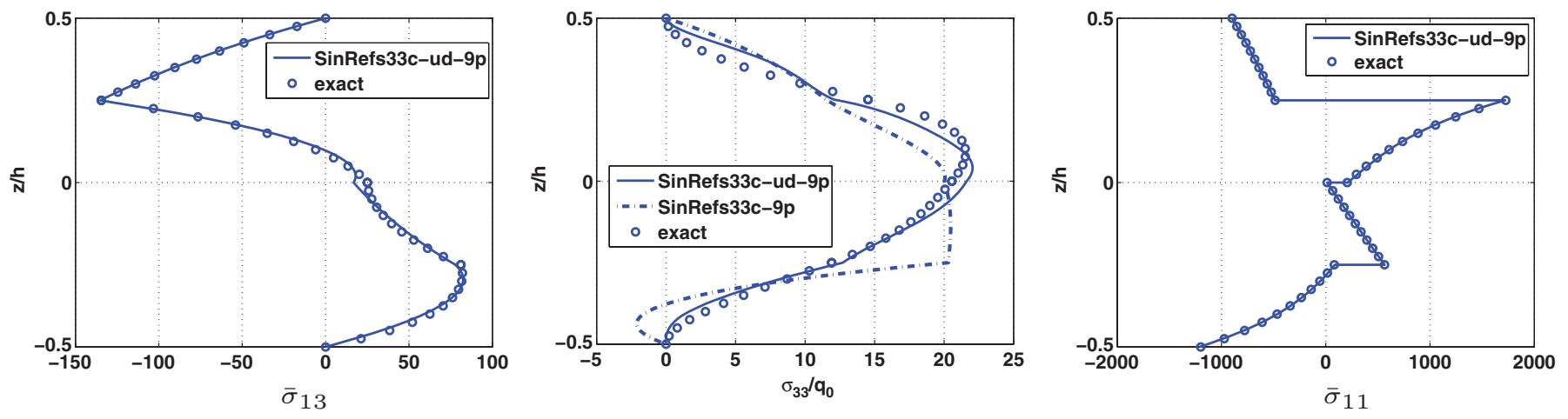

Fig. 7. Distribution of $\bar{\sigma}_{13}$ (left), $\bar{\sigma}_{33}$ (middle), and $\bar{\sigma}_{11}$ (right) along the thickness- $\mathrm{S}=4$-four layers $\left(0^{\circ} / 90^{\circ} / 0^{\circ} / 90^{\circ}\right)-\operatorname{SinRefs} 33 \mathrm{c}-$ ud-9p (color figure available online).

\section{Conclusion}

In this article, two new numerical models, denoted SinRefs33c-ud-9p and SinRefs33c-9p, have been presented and evaluated through different benchmarks under mechanical and thermomechanical loading. Special attention is pointed towards the transverse normal stress effect which plays an important role for thick structures and coupled problems.

Based on the sine equivalent single layer model, a refined kinematic per layer for both the in-plane and transverse displacements is added, improving the bending description for thick plates. All the interface and boundary conditions are exactly satisfied. So, this approach has a strong physical meaning. Finally, the number of unknowns is independent of the number of layers.

A Navier-type closed-form solution has been presented. The present approach is applied to cross-ply laminated plates in cylindrical bending. Several numerical evaluations have proved that this model is satisfactory. Accurate results are obtained for very thick cases under mechanical and thermomechanical loads. So, these models are simple and efficient for a low cost, compared to layerwise approach. This approach allows to calculate the transverse shear and normal stresses directly by the constitutive relation with a very satisfactory accuracy. This study can be extended in the framework of a finite element approach. The goal is to develop a numerical tool that has a good compromise between the computational cost and accuracy.

\section{References}

[1] P. Vidal and O. Polit, A refined sine-based finite element with transverse normal deformation for the analysis of laminated beams under thermomechanical loads, J. Mech. Mater. Struct., vol. 4, no. 6, pp. 1127-1155, 2009.

[2] U. Icardi, Higher-order zig-zag model for analysis of thick composite beams with inclusion of transverse normal stress and sublaminates approximations, Composite Part B: Eng. J., vol. 32, pp. 343-354, 2001.

[3] Y. Tanigawa, H. Murakami, and Y. Ootao, Transient thermal stress analysis of a laminated composite beam, J. Thermal Stresses, vol. 12 , pp. 25-39, 1989
[4] R.D. Mindlin, Influence of rotatory inertia and shear on flexural motions of isotropic, elastic plates, J. Appl. Mech. ASME, vol. 18, pp. 31-38, 1951

[5] P.C. Yang, C.H. Norris, and Y. Stavsky, Elastic wave propagation in heterogeneous plates, Int. J. Solids Struct., vol. 2, pp. 665-684, 1966.

[6] L. Librescu, On the theory of anisotropic elastic shells and plates, Int. J. Solids Struct., vol. 3, pp. 53-68, 1967.

[7] J.M. Whitney and C.T. Sun, A higher order theory for extensional motion of laminated composites, J. Sound Vibr., vol. 30, pp. 85-97, 1973.

[8] K.H. Lo, R.M. Christensen, and F.M. Wu, A higher-order theory of plate deformation. Part II: Laminated plates, J. Appl. Mech. ASME, vol. 44, pp. 669-676, 1977.

[9] J.N. Reddy, A simple higher-order theory for laminated composite plates, J. Appl. Mech. ASME, vol. 51, no. 4, pp. 745-752, 1984.

[10] P. Subramanian, Dynamic analysis of laminated composite beams using higher order theories and finite elements, Compos. Struct., vol. 73, pp. 342-353, 2006.

[11] H. Matsunaga, Assessment of a global higher-order deformation theory for laminated composite and sandwich plates, Compos. Struct., vol. 56, pp. 279-291, 2002.

[12] T. Kant and K. Swaminathan, Analytical solutions for the static analysis of laminated composite and sandwich plates based on a higher order refined theory, Compos. Struct., vol. 56, pp. 329-344, 2002.

[13] A. Barut, E. Madenci, J. Heinrich, and A. Tessler, Analysis of thick sandwich construction by a $\{3,2\}$-order theory, Int. J. Solids Struct., vol. 38, pp. 6063-6077, 2001.

[14] K. Swaminathan and S.S. Patil, Higher order refined computational model with 12 degrees of freedom for the stress analysis of antisymmetric angle-ply plates - analytical solutions, Compos. Struct., vol. 80, pp. 595-608, 2007.

[15] G.M. Cook and A. Tessler, A $\{3,2\}$-order bending theory for laminated composite and sandwich beams, Composite Part B : Eng. J., vol. 29B, pp. 565-576, 1998.

[16] M.K. Rao and Y.M. Desai, Analytical solutions for vibrations of laminated and sandwich plates using mixed theory, Compos. Struct., vol. 63, pp. 361-373, 2004.

[17] A. Tessler, M.S. Annett, and G. Gendron, A $\{1,2\}$-order plate theory accounting for three-dimensional thermoelastic deformations in thick composite and sandwich laminates, Compos. Struct., vol. 52, pp. 67-84, 2001.

[18] J.S.M. Ali, K. Bhaskar, and T.K. Varadan, A new theory for accurate thermal/mechanical flexural analysis of symmetric laminated plates, Compos. Struct., vol. 45, pp. 227-232, 1999.

[19] K. Rohwer, R. Rolfes, and H. Sparr, Higher-order theories for thermal stresses in layered plates, Int. J. Solids Struct., vol. 38, pp. 3673-3687, 2001. 
[20] R. Rolfes, A.K. Noor, and H. Sparr, Evaluation of transverse thermal stresses in composite plates based on first-order shear deformation theory, Comput. Methods Appl. Mech. Eng., vol. 167, pp. 355-368, 1998.

[21] A. Robaldo, Finite element analysis of the influence of temperature profile on thermoelasticity of multilayered plates, Comput. Struct., vol. 84, pp. 1236-1246, 2006.

[22] R.A. Heller and G.W. Swift, Solutions for the multilayer timoshenko beam, Report N VPI-E-71-12, Virginia Polytechnic Institute, BlacksburgVA, 1971.

[23] G.W. Swift and R.A. Heller, Layered beam analysis, J. Engng. Mech. ASCE, vol. 100, pp. 267-282, 1974.

[24] R.P. Shimpi and A.V. Ainapure, A beam finite element based on layerwise trigonometric shear deformation theory, Compos. Struct., vol. 53, pp. 153-162, 2001.

[25] J.N. Reddy, On refined computational models of composite laminates, Int. J. Num. Meth. Eng., vol. 27, pp. 361-382, 1989.

[26] L. Karger, A. Wetzel, R. Rolfes, and K. Rohwer, A three-layered sandwich element with improved transverse shear stiffness and stresses based on FSDT, Comput. Struct., vol. 84, pp. 843-854, 2006.

[27] P.F. Pai and A.N. Palazotto, A higher-order sandwich plate theory accounting for a 3-d stresses, Int. J. Solids Struct., vol. 38, pp. 5045-5062, 2001

[28] E. Carrera, On the use of the murakami's zig-zag function in the modeling of layered plates and shells, Comput. Struct., vol. 82, pp. 541-554, 2004.

[29] M. Gherlone and M. Di Sciuva, Thermo-mechanics of undamaged and damaged multilayered composite plates: A sub-laminates finite approach, Compos. Struct., vol. 81, pp. 125-136, 2007.

[30] E. Carrera, An assessment of mixed and classical theories for the thermal stress analysis of orthotropic multilayered plates, J. Thermal Stresses, vol. 23, pp. 797-831, 2000.

[31] J.M. Whitney, The effect of transverse shear deformation in the bending of laminated plates, J. Comp. Materials, vol. 3, pp. 534-547, 1969.

[32] S.A. Ambartsumyan, Theory of anisotropic plates, J.E. Ashton, Ed., Translated from Russian by T. Cheron, Technomic Publishing Co., Lancaster, PA, 1969.

[33] M. Di Sciuva, Bending, vibration and buckling of simply supported thick multilayered orthotropic plates: An evaluation of a new displacement model, J. Sound Vibr., vol. 105, pp. 425-442, 1986.

[34] K. Bhaskar and T.K. Varadan, Refinement of higher-order laminated plate theories, AIAA J., vol. 27, pp. 1830-1, 1989.

[35] C-Y Lee, D. Liu, and X. Lu, Static and vibration analysis of laminated composite beams with an interlaminar shear stress continuity theory, Int. J. Num. Meth. Eng., vol. 33, pp. 409-424, 1992.

[36] M. Cho and R. Parmerter, Efficient higher-order composite plate theory for general lamination configurations, AIAA J., vol. 31, pp. 1299-1306, 1993.

[37] R.C. Averill and Y.C. Yip, Thick beam theory and finite element model with zig-zag sublaminate approximations, AIAA J., vol. 34, no. 8, pp. 1627-1632, 1996.

[38] V.R. Aitharaju and R.C. Averill, $C^{0}$ zig-zag finite element for analysis of laminated composite beams, J. Engng. Mech. ASCE, vol. 125, pp. 323-330, 1999.

[39] M. Di Sciuva and U. Icardi, Numerical assessment of the core deformability effect on the behavior of sandwich beams, Compos. Struct., vol. 52, pp. 41-53, 2001.

[40] P. Gaudenzi, R. Barboni, and A. Mannini, A finite element evaluation of single-layer and multi-layer theories for the analysis of laminated plates, Compos. Struct., vol. 30, pp. 427-440, 1995.

[41] S. Kapuria, P.C. Dumir, and A. Ahmed, An efficient higher order zigzag theory for composite and sandwich beams subjected to thermal loading, Int. J. Solids Struct., vol. 40, pp. 6613-6631, 2003.

[42] R. Rolfes and K. Rohwer, Improved transverse shear stresses in composite finite elements based on first order shear deformation theory, Int. J. Num. Meth. Eng., vol. 40, pp. 51-60, 1997.
[43] R. Rolfes, K. Rohwer, and M. Ballerstaedt, Efficient linear transverse normal stress analysis of layered composite plates, Comput. Struct., vol. 68, pp. 643-652, 1998.

[44] A.K. Noor, W.S. Burton, and J.M. Peters, Predictor-corrector procedure for stress and free vibration analyses of multilayered composite plates and shells, Comput. Methods Appl. Mech. Eng., vol. 82, pp. 341-364, 1990.

[45] A.K. Noor and W.S. Burton, Assessment of computational models for multilayered composite shells, Appl. Mech. Rev., vol. 43, no. 4, pp. 67-97, 1990.

[46] J.N. Reddy, Mechanics of Laminated Composite Plates-Theory and Analysis, CRC Press, Boca RatonFL, 1997.

[47] E. Carrera, Theories and finite elements for multilayered, anisotropic, composite plates and shells, Arch. Comput. Meth. Engng., vol. 9, pp. 87-140, 2002.

[48] E. Carrera, Historical review of zig-zag theories for multilayered plates and shells, Appl. Mech. Rev., vol. 56, no. 3, pp. 287-308, 2003.

[49] Y.X. Zhang and C.H. Yang, Recent developments in finite elements analysis for laminated composite plates, Compos. Struct., vol. 88, pp. 147-157, 2009

[50] C. Mittelstedt and W. Becker, Free-edge effects in composite laminates, Appl. Mech. Rev., vol. 60, pp. 217-244, 2007.

[51] T. Kant and K. Swaminathan, Estimation of transverse/interlaminar stresses in laminated composites - A selective review and survey of current developments, Compos. Struct., vol. 49 , pp. $65-75,2000$

[52] M. Touratier, A generalization of shear deformation theories for axisymmetric multilayered shells, Int. J. Solids Struct., vol. 29, pp. 1379-1399, 1992.

[53] M. Ganapathi, B.P. Patel, O. Polit, and M. Touratier, A $\mathrm{c}^{1}$ finite element including transverse shear and torsion warping for rectangular sandwich beams, Int. J. Num. Meth. Eng., vol. 45, pp. 47-75, 1999.

[54] E. Carrera and E. Brischetto, Analysis of thickness locking in classical, refined and mixed multilayered plate theories, Compos. Struct., vol. 82, pp. 549-562, 2008.

[55] X. Li and D. Liu, Generalized laminate theories based on double superposition hypothesis, Int. J. Num. Meth. Eng., vol. 40, pp. 1197-1212, 1997.

[56] N.J. Pagano, Exact solutions for composite laminates in cylindrical bending, J. Comp. Materials, vol. 3, pp. 398-411, 1969.

[57] M. Touratier, An efficient standard plate theory, Int. J. Eng. Sci., vol. 29, pp. 901-916, 1991.

[58] O. Polit and M. Touratier, A multilayered/sandwich triangular finite element applied to linear and nonlinear analysis, Compos. Struct., vol. 58, pp. 121-128, 2002.

[59] P. Vidal and O. Polit, A thermomechanical finite element for the analysis of rectangular laminated beams, Finite Elem. Anal. Design, vol. 42, no. 10, pp. 868-883, 2006.

[60] P. Vidal and O. Polit, Assessment of the refined sinus model for the non-linear analysis of composite beams, Compos. Struct., vol. 87, pp. 370-381, 2009. DOI: 10.1016/j.compstruct.2008.02. 007.

[61] K.Y. Sze, R. Chen, and Y.K. Cheung, Finite element model with continuous transverse shear stress for composite laminates in cylindrical bending, Finite Elem. Anal. Design, vol. 31, pp. 153-164, 1998.

[62] W. Zhen and C. Wanji, Refined global-local higher-order theory and finite element for laminated plates, Int. J. Num. Meth. Eng., vol. 69, pp. 1627-1670, 2007.

[63] P. Vidal and O. Polit. A family of sinus finite elements for the analysis of rectangular laminated beams, Compos. Struct., vol. 84, pp. 56-72, 2008. DOI: 10.1016/j.compstruct.2007.06.009.

[64] K. Bhaskar, T.K. Varadan, and J.S.M. Ali, Thermoelastic solutions for orthotropic and anisotropic composite laminates, Composite Part B: Eng. J., vol. 27B, pp. 415-420, 1996. 


\section{Appendix}

\section{Expression of [ $\mathrm{K}$ ]}

The expression of $[\mathbf{K}]$ is given for the SinRefs $33 c-(m+6) p$ model,

$$
\begin{aligned}
{[\mathbf{K}]=} & \sum_{k=1}^{N C} \int_{z_{k}}^{z_{k+1}} \frac{1}{s^{2}}\left[\left[M_{11}\right]^{T}\left[C_{11}^{(k)}\left[M_{11}\right]+C_{13}^{(k)}\left[M_{13}\right]\right]\right. \\
& \left.+\left[M_{13}\right]^{T}\left[C_{13}^{(k)}\left[M_{11}\right]+C_{33}^{(k)}\left[M_{13}\right]\right]\right]+\left[M_{55}\right]^{T} C_{55}^{(k)}\left[M_{55}\right] d z,
\end{aligned}
$$

with

$$
\begin{aligned}
& {\left[M_{11}\right]=\left[-s^{2} \mathcal{L}_{0}(z)-s^{2} \mathcal{L}_{1}(z)-s^{2} \mathcal{L}_{2}(z)-s^{2} \mathcal{L}_{3}(z)-s^{2} \mathcal{L}_{4}(z)\right.} \\
& \left.-s^{3} \mathcal{L}_{50}(z) \ldots-s^{3} \mathcal{L}_{5 m_{0}}(z)\right], \\
& {\left[M_{13}\right]=\left[-s^{2} \mathcal{G}_{0}^{\prime}(z)-s^{2} \mathcal{G}_{1}^{\prime}(z)-s^{2} \mathcal{G}_{2}^{\prime}(z)-s^{2} \mathcal{G}_{3}^{\prime}(z)-s^{2} \mathcal{G}_{4}^{\prime}(z)\right.} \\
& \left.-s^{3} \mathcal{G}_{60}^{\prime}(z) \ldots-s^{3} \mathcal{G}_{6 m_{0}}^{\prime}(z)+s \mathcal{G}_{5 m_{0}}^{\prime}(z)\right], \\
& {\left[M_{55}\right]=\left[\begin{array}{lll}
\mathcal{L}_{0}(z)-s^{2} \mathcal{G}_{0}(z) & \mathcal{L}_{1}(z)-s^{2} \mathcal{G}_{1}(z) & \mathcal{L}_{2}(z)
\end{array}\right.} \\
& \begin{array}{lll}
-s^{2} \mathcal{G}_{2}(z) & \mathcal{L}_{3}(z)-s^{2} \mathcal{G}_{3}(z) \quad \mathcal{L}_{4}(z)-s^{2} \mathcal{G}_{4}(z)
\end{array} \\
& -s^{3} \mathcal{G}_{60}(z)+s\left(\mathcal{G}_{50}(z)+\mathcal{L}_{50}^{\prime}(z)\right) \ldots \\
& \left.-s^{3} \mathcal{G}_{6 m_{0}}(z)+s\left(\mathcal{G}_{5 m_{0}}(z)+\mathcal{L}_{5 m_{0}}^{\prime}(z)\right)\right] \text {. }
\end{aligned}
$$

